\title{
Reduction of pro-inflammatory cytokines in rats following 7-day oral supplementation with a proprietary eggshell membrane-derived product
}

\author{
Kevin J. Ruff ${ }^{1^{*}}$, Dale P. DeVore ${ }^{2}$ \\ ${ }^{1}$ ESM Technologies, LLC, Carthage, USA; *Corresponding Author: kruff@esmingredients.com \\ ${ }^{2}$ Membrell, LLC, Carthage, USA
}

Received 21 January 2014; revised 14 February 2014; accepted 20 February 2014

Copyright (C) 2014 Kevin J. Ruff, Dale P. DeVore. This is an open access article distributed under the Creative Commons Attribution License, which permits unrestricted use, distribution, and reproduction in any medium, provided the original work is properly cited. In accordance of the Creative Commons Attribution License all Copyrights (C 2014 are reserved for SCIRP and the owner of the intellectual property Kevin J. Ruff, Dale P. DeVore. All Copyright (C 2014 are guarded by law and by SCIRP as a guardian.

\section{ABSTRACT}

$\mathrm{NEM}^{\circledR}$ brand eggshell membrane is a novel dietary supplement that has been clinically shown to alleviate arthritis joint pain and stiffness; however the mechanism of action is not well understood. Preliminary evidence from an in vitro study of $\mathrm{NEM}^{\circledR}$ indicated that the mechanism of action may be based on the reduction of pro-inflammatory cytokines. In vivo studies were therefore initiated to evaluate the effects of $\mathrm{NEM}^{\circledR}$ on pro-inflammatory and anti-inflammatory cytokines following oral administration in rats. NEM ${ }^{\circledR}$ was administered daily at doses of $6.13 \mathrm{mg} / \mathrm{kg} \mathrm{bw} / \mathrm{day}$ (Study 1), $10.0 \mathrm{mg} / \mathrm{kg}$ bw/day (Study 2), or at doses of 0 (control), 26.0 or $\mathbf{5 2 . 0}$ $\mathrm{mg} / \mathrm{kg}$ bw/day (Study 3) by oral gavage for 7 consecutive days. Inflammation was induced in the Study 3 rats by intraperitoneal injection of lipopolysaccharide. Changes in plasma cytokine levels from baseline following 7 days of oral supplementation with $\mathrm{NEM}^{\circledR}$ at $6.13 \mathrm{mg} / \mathrm{kg} \mathrm{bw/}$ day (Study 1 ) were statistically significant at Day 8 for IL-2, TIMP-1 and VEGF, at Day 21 for IL-10, and at Day 35 for MCP-1, MCP-3 and TIMP-1, and at $10.0 \mathrm{mg} / \mathrm{kg}$ bw/day (Study 2) were statistically significant at Day 8 for VEGF, at Day 21 for MIP-1 $\beta$, MIP-2 and VEGF, and at Day 35 for MCP-3, MIP-1 $\beta$, MIP-2 and VEGF. Changes in serum cytokine levels versus control at 26.0 $\mathrm{mg} / \mathrm{kg}$ bw/day (Study 3) were statistically significant at all time-points for IL-1 $\beta$ and at $\mathbf{1 . 5}$ hours for IL-10, and at $52.0 \mathrm{mg} / \mathrm{kg}$ bw/day (Study 3) were statistically significant at $\mathbf{1 . 5}$ hours for IFN- $\gamma$, IL-1 $\beta$ and IL-10, and at 3 hours for IL-1 $\beta$, and at $\mathbf{2 4}$ hours for IL-10. Taken together, these studies demonstrate that oral supplementation with $\mathrm{NEM}^{\circledR}$ can influence both early-phase proinflammatory cytokines like IL-1 $\beta$ and TNF- $\alpha$ (Study 3), as well as later-phase cytokines like MCP-1, MIP-1 $\alpha$ \& $\beta$, RANTES and VEGF (Study 1 $\& 2$ ). These studies provide a possible basis for the mechanism of action of $\mathrm{NEM}^{\circledR}$ in vivo.

\section{KEYWORDS}

\section{Pro-Inflammatory Cytokines; Eggshell Membrane}

\section{INTRODUCTION}

Many human diseases are characterized by chronic inflammation which ultimately leads to tissue destruction. Inflammatory arthritides like rheumatoid arthritis (RA) and osteoarthritis (OA) are classic examples of such diseases and the roles that inflammatory chemokines and cytokines play in the pathogenesis of these diseases are fairly well accepted [1-6]. Corticosteroids, non-steroidal anti-inflammatory drugs (NSAIDs) (e.g. ibuprofen, diclofenac, celecoxib), and inflammatory cytokine-specific biologics (e.g. etanercept, infliximab, adalimumab) are commonly prescribed to address the underlying inflammation of these debilitating conditions. While some of these treatments have demonstrated good efficacy in randomized controlled clinical trials (RCTs), they are also known to have significant and sometimes severe side effects [7-10]. $\mathrm{NEM}^{\circledR}$ brand eggshell membrane has previously demonstrated good efficacy in relieving pain and stiffness associated with OA of the knee in an RCT [11] and has shown similar efficacy in limited trials for 
other affected joints [12,13] with no reports of any significant side effects during these trials.

Eggshell membrane is primarily composed of fibrous proteins such as Collagen Type I [14]. However, eggshell membranes have also been shown to contain other bioactive components, namely glycosaminoglycans (e.g. dermatan sulfate [15], chondroitin sulfate [15], hyaluronic acid [16], etc.). ESM Technologies, LLC (Carthage, MO USA) has developed methods to efficiently and effectively separate eggshell membrane from eggshells on a commercial metric-ton scale. The isolated membrane is then partially hydrolyzed using a proprietary process and dry-blended to produce $\mathrm{NEM}^{\circledR}$ brand eggshell membrane. Compositional analysis of $\mathrm{NEM}^{\circledR}$ conducted by ESM has identified a high content of protein and moderate quantities of glucosamine (up to $1 \%$ by dry weight), chondroitin sulfate (up to $1 \%$ ), hyaluronic acid (up to $2 \%$ ), and collagen (Type I, up to 5\%).

Although NEM ${ }^{\circledR}$ has been clinically shown to alleviate joint pain and stiffness from arthritis, the mechanism of action of this eggshell membrane preparation is not well understood. Preliminary evidence from an in vitro study of $\mathrm{NEM}^{\circledR}$ indicated that the basis for the mechanism of action may be via the reduction of pro-inflammatory cytokines [17]. In vivo studies were therefore initiated to evaluate the effects of $\mathrm{NEM}^{\circledR}$ on pro-inflammatory and anti-inflammatory cytokines following oral administration in rats. The results of these preliminary studies are reported herein.

\section{MATERIALS AND METHODS}

\subsection{Animals, Care and Diet}

Studies were conducted utilizing the facilities and staff of Charles River Laboratories (Spencerville, OH) (Study $1 \& 2$ ) and Ricerca Biosciences (Taipei, Taiwan) (Study $3)$. Animals were housed and cared for in general accordance with the "Guide for the Care and Use of Laboratory Animals" (National Academies Press, Washington, D.C. USA, 1996). Male Sprague Dawley rats were obtained from Harlan Sprague Dawley, Inc., Indianapolis, IN USA (Study 1 \& 2) and BioLASCO Taiwan Co., Ltd. (a Charles River licensee), Taipei, Taiwan (Study 3) at approximately 7 - 10 weeks of age. Upon receipt, tags with unique identification numbers were used to individually identify the animals. Cage cards displaying the study number, animal number, and sex were affixed to each cage. The rats were acclimatized for 5 days prior to study commencement and were observed daily for overt physical or behavioral abnormalities, general health/ moribundity, and mortality. Healthy rats weighing $300 \pm 20$ $\mathrm{g}$ were randomized into groups of three and were housed in cages under standard experimental conditions $\left(22^{\circ} \mathrm{C} \pm\right.$ $3^{\circ} \mathrm{C} ; 30 \%$ - 70\% humidity; 12-hour light/dark cycle; minimum 10 room air changes per hour) and had access to standard rat chow [PMI Certified Rodent Chow \#5002 (PMI Nutrition International, St. Louis, MO USA) (Study 1 \& 2) or Laboratory Rodent Diet MF-18 (Oriental Yeast Co., Ltd., Tokyo, Japan)(Study 3)] and water ad libitum.

\subsection{Test Article Preparation and Dosing}

The test article was prepared by suspending NEM ${ }^{\circledR}$ powder (ESM Technologies, LLC, Carthage, MO USA) in $0.5 \%$ methylcellulose (Sigma-Aldrich, St. Louis, MO USA) in distilled water at a concentration of 0.613 $\mathrm{mg} / \mathrm{mL}$ (Study 1), $1.0 \mathrm{mg} / \mathrm{mL}$ (Study 2), or $2.6 \mathrm{mg} / \mathrm{mL}$ and $5.2 \mathrm{mg} / \mathrm{mL}$ (Study 3), corresponding to a dose volume of $10 \mathrm{~mL} / \mathrm{kg}$. The test article was stored at approximately $4^{\circ} \mathrm{C}$ with constant stirring between daily uses. The $\mathrm{NEM}^{\circledR}$ suspension was administered daily to groups of 3 rats (Study $1 \& 2$ ) or groups of 8 rats (Study 3) at doses of $6.13 \mathrm{mg} / \mathrm{kg} \mathrm{bw} /$ day (Study 1), $10.0 \mathrm{mg} / \mathrm{kg}$ bw/day (Study 2), or at doses of 0 (control, vehicle only), $26.0 \mathrm{mg} / \mathrm{kg}$ bw/day, or $52.0 \mathrm{mg} / \mathrm{kg}$ bw/day (Study 3) by oral gavage for 7 consecutive days. The rats were observed twice daily following administration of the test article for mortality and clinical abnormalities during the study period.

\subsection{Induction of Inflammation (Study 3)}

Inflammation was induced in the Study 3 rats by intraperitoneal (i.p.) injection $(2.5 \mathrm{mg} / \mathrm{kg})$ of a solution of lipopolysaccharide (LPS) (E. coli serotype 055:B5, Sigma-Aldrich, St. Louis, MO USA) in pyrogen free saline (Taiwan Biotech Co., Ltd., Taoyuan, Taiwan). Control rats received an i.p. injection of saline only.

\subsection{Blood Collection and Cytokine Measurement}

Blood samples $(\sim 0.5 \mathrm{~mL})$ were collected via jugular vein (Study $1 \& 2$ ) or tail vein (Study 3) pre-dose (Day 0) (all studies) and on Days 8, 21 and 35 (Study 1 \& 2) or $1.5,3$ and 24 hours post LPS injection (Study 3). Blood samples were processed at the time of collection into plasma samples (Study $1 \& 2$ ) or serum samples (Study 3) and were stored at $-70^{\circ} \mathrm{C}$ until cytokine determination could be performed.

Cytokine determination for Study 1 \& 2 was accomplished utilizing the facilities and services of Rules Based Medicine, Inc., Austin, TX USA using their Rodent $\mathrm{MAP}^{\circledR}$ multi-analyte profile platform following the manufacturer's instructions. In this instance, the levels of 42 different biomarkers, chemokines and cytokines were evaluated, however only 16 of these which are related to inflammation [Granulocyte Chemotactic Protein 2 (GCP2), Interferon gamma (IFN- $\gamma$ ), Interleukin 1 beta (IL-1 $\beta$ ), 
IL-2, IL-4, IL-6, IL-10, Monocyte Chemotactic Protein 1 (MCP-1), MCP-3, Macrophage Inflammatory Protein 1 alpha (MIP-1 $\alpha$ ), MIP-1 $\beta$, MIP-2, Regulated upon Activation Normal T-cell Expressed and Secreted (RANTES), Tissue Inhibitor of Matalloproteinase Type 1 (TIMP-1), Tumor Necrosis Factor alpha (TNF- $\alpha$ ), and Vascular Endothelial Growth Factor (VEGF)] are reported herein. Cytokine determination for Study 3 was performed by Ricerca Biosciences, LLC, Bothell, WA USA using the Luminex xMAP ${ }^{\circledR}$ bead-based multiplex platform (Austin, TX USA) following the manufacturer's instructions. In this instance, the levels of 5 chemokines/cytokines related to inflammation (IFN- $\gamma$, IL-1 $\beta$, IL-6, IL-10, TNF- $\alpha$ ) were evaluated and are reported herein.

\subsection{Statistical Analysis}

Comparisons of baseline data between groups (Study 3) were made with a Kruskal-Wallis test for multiple independent samples to validate randomization. Statistical significance was accepted at an $\alpha$ value of $<0.05$. Postbaseline statistical analyses were done as repeated measures univariate Analysis of Variance (rm-ANOVA) versus baseline (Study $1 \& 2$ ) or versus control (Study 3). Items found to have statistical significance with rm-ANOVA were then compared using a post hoc test for repeated measures. Statistical significance was accepted at an $\alpha$ value of $<0.05$ for both determinations. In cases where post-baseline cytokine values were below the Limit of Quantitation (LOQ), a value of $1 / 2 \mathrm{LOQ}$ (well above the Limit of Detection for the assays) was incorporated for statistical calculations as opposed to incorporating zero values (Study 1 \& 2). This substitution approach was developed in consultation with the assay manufacturer and cases where this approach was used are denoted in the data tables. Additionally, data points were excluded in cases where there was $>35 \%$ variance between replicates (Study 3). This occurred at a rate of $<4 \%$ in the overall dataset and appeared to be randomly distributed throughout. SYSTAT software (version 13) was used for all statistical analyses [18].

\section{RESULTS}

Changes in plasma cytokine levels from baseline following 7 days of oral supplementation with $\mathrm{NEM}^{\circledR}$ at $6.13 \mathrm{mg} / \mathrm{kg}$ bw/day (Study 1, Table 1) were statistically significant at Day 8 for IL-2 (153\% increase, $p=0.033)$, TIMP-1 (11.2\% reduction, $p=0.002)$ and VEGF $(27.8 \%$ reduction, $p=0.022)$, at Day 21 for IL-10 (65.1\% reduction, $p=0.033)$, and at Day 35 for MCP-1 (30.0\% reduction, $p=0.034)$, MCP-3 (26.6\% reduction, $p=0.007$ ) and TIMP-1 (14.6\% reduction, $p=0.032)$. There were non-detectable levels of MIP-1 $\beta$ at Day 21 and MIP-2 and TNF- $\alpha$ at Day 35.
Table 1. Change in plasma cytokine levels from baseline in healthy rats following 7 days of oral supplementation with $\mathrm{NEM}^{\circledR}$ at $6.13 \mathrm{mg} / \mathrm{kg}$ bw/day.

\begin{tabular}{ccccc}
\hline & $\begin{array}{c}\text { Baseline } \\
(\text { Day } 0)\end{array}$ & $\begin{array}{c}\text { NEM } \\
(\text { Day } 8)\end{array}$ & $\begin{array}{c}\text { NEM } \\
(\text { Day 21) }\end{array}$ & $\begin{array}{c}\text { NEM } \\
(\text { Day 35) }\end{array}$ \\
\cline { 2 - 5 } & $\mathrm{n}=3$ & $\mathrm{n}=3$ & $\mathrm{n}=3$ & $\mathrm{n}=3$ \\
\hline GCP-2 $^{\mathrm{a}}$ & $0.07 \pm 0.02$ & $0.22 \pm 0.10$ & $0.24 \pm 0.07^{\dagger}$ & $0.06 \pm 0.02$ \\
IFN- $^{\mathrm{b}}$ & $<$ LOQ & $<$ LOQ & $<$ LOQ & $<$ LOQ \\
IL-1 $^{\mathrm{a}}$ & $1.29 \pm 0.99$ & $0.72 \pm 0.34$ & $0.62 \pm 0.22$ & $0.30 \pm 0.12^{\mathrm{c}}$ \\
IL-2 $^{\mathrm{b}}$ & $11.2 \pm 6.2$ & $28.3 \pm 9.0^{*}$ & $33.9 \pm 23.6$ & $26.0 \pm 13.0$ \\
IL-4 $^{\mathrm{b}}$ & $<\mathrm{LOQ}$ & $<\mathrm{LOQ}$ & $<\mathrm{LOQ}$ & $<\mathrm{LOQ}$ \\
IL-6 $^{\mathrm{b}}$ & $<\mathrm{LOQ}$ & $<\mathrm{LOQ}$ & $<\mathrm{LOQ}$ & $<\mathrm{LOQ}$ \\
IL-10 $^{\mathrm{b}}$ & $616 \pm 98$ & $503 \pm 85$ & $215 \pm 105^{*}$ & $477 \pm 62$ \\
MCP-1 $^{\mathrm{b}}$ & $457 \pm 65$ & $449 \pm 91$ & $553 \pm 144$ & $320 \pm 101^{*}$ \\
MCP-3 $^{\mathrm{b}}$ & $222 \pm 51$ & $207 \pm 39$ & $256 \pm 70$ & $163 \pm 42^{*}$ \\
MIP-1 $^{\mathrm{a}}$ & $0.26 \pm 0.05$ & $0.17 \pm 0.08$ & $0.15 \pm 0.03$ & $0.24 \pm 0.06$ \\
MIP-1 $^{\mathrm{b}}$ & $28.7 \pm 11.5$ & $44.2 \pm 9.1$ & $39.0 \pm 0.0^{\mathrm{c}}$ & $27.4 \pm 17.0$ \\
MIP-2 $^{\mathrm{b}}$ & $3.0 \pm 0.7$ & $3.3 \pm 0.7$ & $3.6 \pm 1.2$ & $3.6 \pm 0.0^{\mathrm{c}}$ \\
RANTES $^{\mathrm{b}}$ & $86.2 \pm 36.6$ & $152 \pm 92$ & $319 \pm 70^{\dagger}$ & $62.0 \pm 22.5$ \\
TIMP-1 $^{\mathrm{a}}$ & $8.9 \pm 1.4$ & $7.9 \pm 1.3 *$ & $8.3 \pm 0.6$ & $7.6 \pm 1.1^{*}$ \\
TNF- $^{\mathrm{a}}$ & $0.05 \pm 0.03$ & $0.05 \pm 0.04^{\mathrm{c}}$ & $0.05 \pm 0.04^{\mathrm{c}}$ & $0.07 \pm 0.0^{\mathrm{c}}$ \\
VEGF $^{\mathrm{b}}$ & $227 \pm 38$ & $164 \pm 40^{*}$ & $196 \pm 55$ & $208 \pm 30$ \\
\hline
\end{tabular}

Values represent means \pm standard deviation, $\mathrm{a}=\mathrm{ng} / \mathrm{mL}, \mathrm{b}=\mathrm{pg} / \mathrm{mL},<\mathrm{LOQ}$ = below limit of quantitation, $P$-values determined by repeated measures ANOVA versus baseline, ${ }^{*} P<0.05,{ }^{\dagger} P<0.10$, c $=$ contained cases where values measured were below the Limit of Quantitation (LOQ) wherein values of $1 / 2 \mathrm{LOQ}$ were incorporated for statistical calculations.

Changes in plasma cytokine levels versus baseline following 7 days of oral supplementation with $\mathrm{NEM}^{\circledR}$ at $10.0 \mathrm{mg} / \mathrm{kg}$ bw/day (Study 2, Table 2) were statistically significant at Day 8 for VEGF (50.1\% reduction, $p=$ 0.038 ), at Day 21 for $\mathrm{MIP}-1 \beta$ (84.8\% reduction, $p=$ $0.022)$, MIP-2 (77.1\% reduction, $p=0.005)$ and VEGF (61.5\% reduction, $p=0.014)$, and at Day 35 for MCP-3 (67.2\% reduction, $p=0.047)$, MIP- $1 \beta$ (88.4\% reduction, $p=0.002)$, MIP-2 (76.5\% reduction, $p=0.006)$ and VEGF (66.4\% reduction, $p=0.002)$. There were trends toward significance at Day 8 for MIP-2 (64.0\% reduction, $p=0.063)$, at Day 21 for MCP-3 (61.9\% reduction, $p=$ $0.081)$ and TNF- $\alpha$ (70.0\% reduction, $p=0.097)$, and at Day 35 for GCP-2 (53.8\% reduction, $p=0.075)$, IL-2 (69.0\% reduction, $p=0.098)$ and MCP-1 (67.3\% reduction, $p=0.079)$. There were non-detectable levels of IL-2, MIP-2 and TIMP-1 at Day 35.

There were no differences in serum cytokine levels between groups (control, $26.0 \mathrm{mg} / \mathrm{kg}$ bw/day or 52.0 $\mathrm{mg} / \mathrm{kg}$ bw/day) at baseline for any of the five cytokines evaluated (IFN- $\gamma$, IL-1 $\beta$, IL-6, IL-10, TNF- $\alpha$ )(Study 3, Table 3). Changes in serum cytokine levels versus control following 7 days of oral supplementation with $\mathrm{NEM}^{\circledR}$ at $26.0 \mathrm{mg} / \mathrm{kg}$ bw/day (Study 3, Table 4) with 
Table 2. Change in plasma cytokine levels from baseline in healthy rats following 7 days of oral supplementation with $\mathrm{NEM}^{\circledR}$ at $10.0 \mathrm{mg} / \mathrm{kg}$ bw/day.

\begin{tabular}{ccccc}
\hline & $\begin{array}{c}\text { Baseline } \\
(\text { Day } 0)\end{array}$ & $\begin{array}{c}\text { NEM } \\
(\text { Day } 8)\end{array}$ & $\begin{array}{c}\text { NEM } \\
(\text { Day 21) }\end{array}$ & $\begin{array}{c}\text { NEM } \\
(\text { Day 35) }\end{array}$ \\
\cline { 2 - 5 } & $\mathrm{n}=3$ & $\mathrm{n}=3$ & $\mathrm{n}=3$ & $\mathrm{n}=3$ \\
\hline GCP-2 $^{\mathrm{a}}$ & $0.13 \pm 0.05$ & $0.06 \pm 0.04$ & $0.02 \pm 0.03$ & $0.06 \pm 0.02^{\dagger}$ \\
IFN- $^{\mathrm{b}}$ & $<\mathrm{LOQ}$ & $<\mathrm{LOQ}$ & $<\mathrm{LOQ}$ & $<\mathrm{LOQ}$ \\
IL-1 $^{\mathrm{a}}$ & $<\mathrm{LOQ}$ & $<\mathrm{LOQ}$ & $<\mathrm{LOQ}$ & $<\mathrm{LOQ}$ \\
IL-2 $^{\mathrm{b}}$ & $108 \pm 44$ & $31.3 \pm 21.3$ & $25.3 \pm 14.1^{\mathrm{c}}$ & $33.5 \pm 0.0^{\mathrm{c}}$ \\
IL-4 $^{\mathrm{b}}$ & $<\mathrm{LOQ}$ & $<\mathrm{LOQ}$ & $<\mathrm{LOQ}$ & $<\mathrm{LOQ}$ \\
IL-6 $^{\mathrm{b}}$ & $<\mathrm{LOQ}$ & $<\mathrm{LOQ}$ & $<\mathrm{LOQ}$ & $<\mathrm{LOQ}$ \\
IL-10 $^{\mathrm{b}}$ & $460 \pm 265$ & $305 \pm 15$ & $314 \pm 25$ & $294 \pm 83$ \\
MCP-1 $^{\mathrm{b}}$ & $721 \pm 233$ & $439 \pm 113$ & $250 \pm 122$ & $236 \pm 28^{\dagger}$ \\
MCP-3 $^{\mathrm{b}}$ & $354 \pm 93$ & $226 \pm 72$ & $135 \pm 44^{\dagger}$ & $116 \pm 6^{*}$ \\
MIP-1 $^{\mathrm{a}}$ & $<\mathrm{LOQ}$ & $<\mathrm{LOQ}$ & $<\mathrm{LOQ}$ & $<\mathrm{LOQ}$ \\
MIP-1 $^{\mathrm{b}}$ & $250 \pm 31$ & $81 \pm 103$ & $38 \pm 46^{*}$ & $29 \pm 16^{*}$ \\
MIP-2 $^{\mathrm{b}}$ & $15.3 \pm 1.5$ & $5.5 \pm 3.4^{\mathrm{c}}$ & $3.5 \pm 0.2^{\mathrm{c}^{*}}$ & $3.6 \pm 0.0^{\mathrm{c}^{*}}$ \\
RANTES $^{\mathrm{b}}$ & $195 \pm 118$ & $93 \pm 100$ & $23 \pm 20$ & $20 \pm 4$ \\
TIMP-1 $^{\mathrm{a}}$ & $0.28 \pm 0.16$ & $0.09 \pm 0.06^{\mathrm{c}}$ & $0.08 \pm 0.03^{\mathrm{c}}$ & $0.09 \pm 0.00^{\mathrm{c}}$ \\
TNF- $^{\mathrm{a}}$ & $0.20 \pm 0.09$ & $0.06 \pm 0.06$ & $0.06 \pm 0.03^{\mathrm{c} \dagger}$ & $0.04 \pm 0.03^{\mathrm{c}}$ \\
VEGF $^{\mathrm{b}}$ & $429 \pm 42$ & $214 \pm 75^{*}$ & $165 \pm 25^{*}$ & $144 \pm 33^{*}$ \\
\hline
\end{tabular}

Values represent means \pm standard deviation, $\mathrm{a}=\mathrm{ng} / \mathrm{mL}, \mathrm{b}=\mathrm{pg} / \mathrm{mL},<\mathrm{LOQ}$ = below limit of quantitation, $P$-values determined by repeated measures ANOVA versus baseline, ${ }^{*} P<0.05,{ }^{\dagger} P<0.10, \mathrm{c}=$ contained cases where values measured were below the Limit of Quantitation (LOQ) wherein values of $1 / 2 \mathrm{LOQ}$ were incorporated for statistical calculations.

Table 3. Mean serum cytokine concentrations $(\mathrm{pg} / \mathrm{mL})$ in NEM-supplemented and control groups at baseline.

\begin{tabular}{cccc}
\hline & $\begin{array}{c}\text { Control } \\
(0 \mathrm{mg} / \mathrm{kg})\end{array}$ & $\begin{array}{c}\text { NEM } \\
(26 \mathrm{mg} / \mathrm{kg})\end{array}$ & $\begin{array}{c}\text { NEM } \\
(52 \mathrm{mg} / \mathrm{kg})\end{array}$ \\
\cline { 2 - 4 } & $\mathrm{n}=8$ & $\mathrm{n}=8$ & $\mathrm{n}=8$ \\
\hline IFN- $\gamma$ & $2.49 \pm 0.16$ & $2.40 \pm 0.00$ & $2.49 \pm 0.27$ \\
IL-1 $\beta$ & $15.8 \pm 10.0$ & $13.0 \pm 5.5$ & $18.6 \pm 13.2$ \\
TNF- $\alpha$ & $11.1 \pm 2.0$ & $10.2 \pm 0.7$ & $11.2 \pm 2.9$ \\
IL-6 & $9.80 \pm 0.00$ & $9.96 \pm 1.14$ & $10.2 \pm 1.1$ \\
IL-10 & $10.2 \pm 1.0$ & $9.80 \pm 0.00$ & $10.0 \pm 0.6$ \\
\hline
\end{tabular}

Values represent means \pm standard deviation, $P$-values determined by Kruskal-Wallis test for multiple independent samples, ${ }^{*} P<0.05,{ }^{\dagger} P<0.10$.

subsequent inflammatory challenge (LPS, i.p.) were statistically significant at 1.5 hours (43.7\% reduction, $p=$ $0.013), 3$ hours $(28.8 \%$ reduction, $p=0.034)$ and 24 hours (20.8\% reduction, $p=0.006)$ for $\mathrm{IL}-1 \beta$ and at 1.5 hours $(27.6 \%$ reduction, $p=0.028)$ for IL-10. There was a trend toward significance at 24 hours for IL-10 (74.6\% increase, $p=0.097$ ). No other changes in serum cytokine levels were statistically significant at this dose level.

Changes in serum cytokine levels versus control following 7 days of oral supplementation with $\mathrm{NEM}^{\circledR}$ at
$52.0 \mathrm{mg} / \mathrm{kg}$ bw/day (Study 3, Table 5) with subsequent inflammatory challenge (LPS, i.p.) were statistically significant at 1.5 hours for IFN- $\gamma$ (33.5\% reduction, $p=$ $0.047)$, IL-1 $\beta$ (39.4\% reduction, $p=0.003$ ) and IL-10 (29.8\% reduction, $p=0.015$ ), and at 3 hours for IL- $1 \beta$ (23.9\% reduction, $p=0.044$ ), and at 24 hours for IL-10 (57.5\% increase, $p=0.021$ ). There was a trend toward significance at 24 hours for IL-1 $\beta$ (9.3\% reduction, $p=$ 0.093). No other changes in serum cytokine levels were statistically significant at this dose level.

\section{DISCUSSION}

Although OA has not traditionally been considered an inflammatory arthropathy, the scientific understanding of the pathophysiological progression of the disease has been gradually trending towards that of a disease involving the "whole joint" with significant localized inflammation [19]. Evidence of an inflammatory process in OA is reflected in many of the clinical symptoms of the progressive disease, including swelling of affected joints,

Table 4. Change in mean serum cytokine concentrations (pg/mL) in 7-day NEM-supplemented (26 mg/kg bw/day) and control groups from baseline at 1.5, 3, and 24 hours post LPS treatment.

\begin{tabular}{|c|c|c|c|c|}
\hline & \multirow{2}{*}{$\begin{array}{l}\text { Hours post- } \\
\text { treatment }\end{array}$} & Control & NEM & \multirow{2}{*}{$\begin{array}{l}\text { \% Difference } \\
\text { (NEM-vs-ctrl) }\end{array}$} \\
\hline & & $\begin{array}{c}(0 \mathrm{mg} / \mathrm{kg}) \\
\mathrm{n}=8\end{array}$ & $\begin{array}{c}(26 \mathrm{mg} / \mathrm{kg}) \\
\mathrm{n}=8\end{array}$ & \\
\hline \multirow[t]{4}{*}{ IFN- $\gamma$} & Baseline & $2.49 \pm 0.16$ & $2.40 \pm 0.00$ & -3.5 \\
\hline & 1.5 & $6.35 \pm 2.48$ & $4.88 \pm 2.60$ & -23.2 \\
\hline & 3 & $135 \pm 43$ & $144 \pm 85$ & 6.2 \\
\hline & 24 & $3.55 \pm 2.18$ & $2.49 \pm 0.14$ & -29.8 \\
\hline \multirow{4}{*}{ IL- $1 \beta$} & Baseline & $15.8 \pm 10.0$ & $13.0 \pm 5.5$ & -17.9 \\
\hline & 1.5 & $62.4 \pm 17.1$ & $35.1 \pm 16.7^{*}$ & $-43.7^{*}$ \\
\hline & 3 & $87.9 \pm 23.5$ & $62.6 \pm 15.9^{*}$ & $-28.8^{*}$ \\
\hline & 24 & $12.6 \pm 2.1$ & $9.96 \pm 0.42^{*}$ & $-20.8^{*}$ \\
\hline \multirow[t]{4}{*}{ TNF- $\alpha$} & Baseline & $11.1 \pm 2.0$ & $10.2 \pm 0.7$ & -7.6 \\
\hline & 1.5 & $1157 \pm 828$ & $934 \pm 332$ & -19.3 \\
\hline & 3 & $84.5 \pm 46.7$ & $75.5 \pm 28.7$ & -10.7 \\
\hline & 24 & $9.80 \pm 0.00$ & $9.80 \pm 0.00$ & 0.0 \\
\hline \multirow[t]{4}{*}{ IL-6 } & Baseline & $9.80 \pm 0.00$ & $9.96 \pm 1.14$ & 1.7 \\
\hline & 1.5 & $321 \pm 175$ & $385 \pm 182$ & 20.0 \\
\hline & 3 & $386 \pm 172$ & $329 \pm 133$ & -14.8 \\
\hline & 24 & $10.0 \pm 0.6$ & $10.7 \pm 2.3$ & 6.6 \\
\hline \multirow[t]{4}{*}{ IL-10 } & Baseline & $10.2 \pm 1.0$ & $9.80 \pm 0.00$ & -3.8 \\
\hline & 1.5 & $42.7 \pm 12.3$ & $30.9 \pm 8.3^{*}$ & $-27.6^{*}$ \\
\hline & 3 & $18.7 \pm 5.6$ & $19.3 \pm 7.4$ & 3.1 \\
\hline & 24 & $14.2 \pm 3.2$ & $24.9 \pm 11.5^{\dagger}$ & $74.6^{\dagger}$ \\
\hline
\end{tabular}

Values represent means \pm standard deviation. $P$-values determined by repeated measures ANOVA, ${ }^{*} p<0.05,{ }^{\dagger} p<0.10$. ctrl $=$ control. 
Table 5. Mean serum cytokine concentrations $(\mathrm{pg} / \mathrm{mL})$ in 7-day NEM-supplemented (52 $\mathrm{mg} / \mathrm{kg}$ bw/day) and control groups at baseline and 1.5, 3, and 24 hours post LPS treatment.

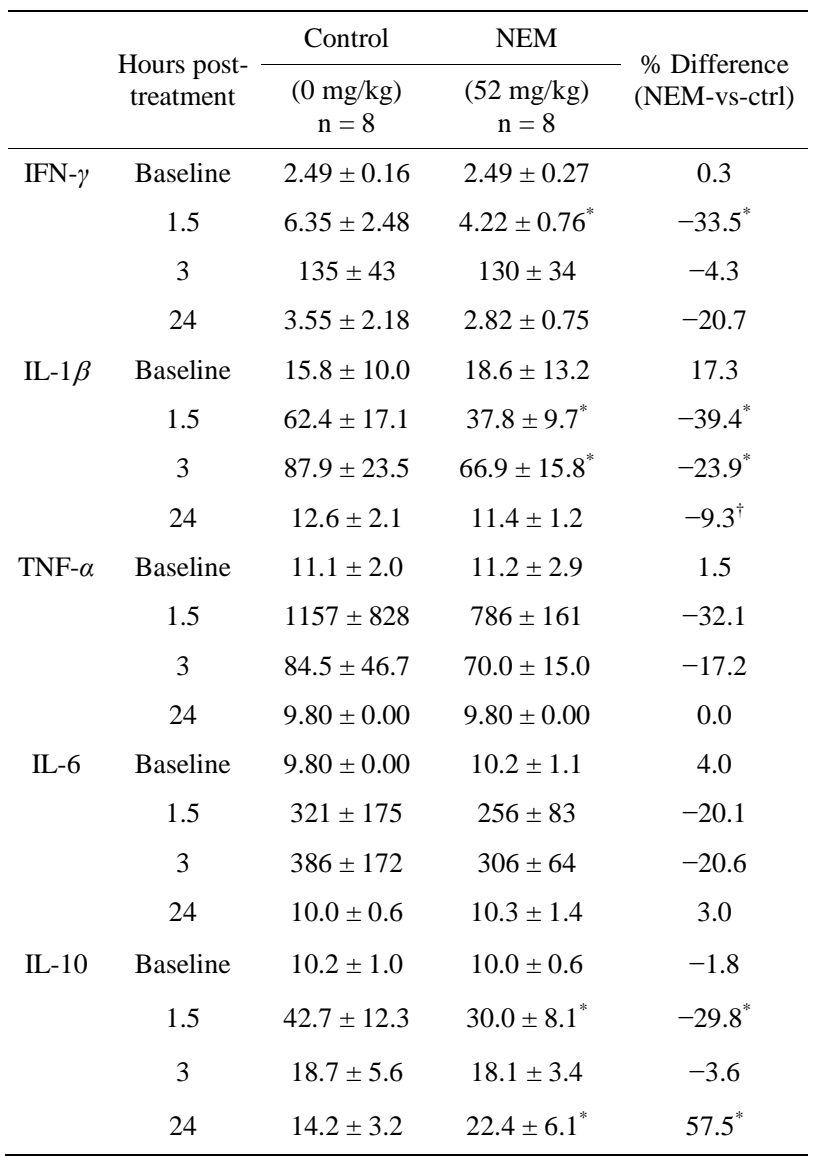

Values represent means \pm standard deviation. $P$-values determined by repeated measures ANOVA, ${ }^{*} p<0.05,{ }^{\dagger} p<0.10$. ctrl $=$ control.

synovial effusion, and joint stiffness [20]. This clinical evidence is supported by immunochemical and histological data from numerous studies showing infiltration of the joint synovium by immune cells, primarily macrophages and mononuclear lymphocytes such as T-cells [20-22] accompanied by subsequent inflammatory cytokine expression [23] and synovial fibroblast activation [24].

The two primary mediators of arthritis inflammation are IL- $1 \beta$ and TNF- $\alpha$. These cytokines have been identified as targets for OA treatment $[25,26]$ and there are multiple FDA-approved biologic drugs (etanercept, infliximab, adalimumab, etc.) for this indication (mostly RA). These cytokines, in an autocrine/paracrine manner, auto-amplify their own expression and induce chondrocytes to produce matrix metalloproteinases (MMPs), chemokines (IL-8, MCP-1, MIP- $1 \alpha$, MIP-1 $\beta$, RANTES, etc.), nitric oxide, and prostaglandins $[19,26]$. This leads to localized tissue destruction, immune cell infiltration, inhibition of cartilage matrix synthesis, and increased pain sensitivity, among others.
The eggshell membrane derived product $\mathrm{NEM}^{\circledR}$ has previously been shown in vitro to reduce a number of pro-inflammatory cytokines in human immune cells following inflammatory challenge (with phyto-mitogens), with this effect being most pronounced for IFN- $\gamma$ and TNF- $\alpha$ [17]. In this paper, we reported in vivo support for the reduction of circulating pro-inflammatory cytokines following oral supplementation with $\mathrm{NEM}^{\circledR}$ in both healthy rats (Study 1 \& 2) and inflammatory-challenged rats (Study 3).

While not statistically significant, $\mathrm{NEM}^{\circledR}$ appeared to demonstrate trends toward reduction in healthy rats for both IL-1 $\beta$ (6.13 mg/kg bw/day)(Study 1 ) and TNF- $\alpha$ $(10.0 \mathrm{mg} / \mathrm{kg}$ bw/day)(Study 2). Interestingly, there were statistically significant effects at both dose levels for nearly all of the chemokines (MCP-1, MIP- $1 \alpha$, MIP- $1 \beta$, RANTES, VEGF) currently understood to be key players in OA/RA inflammation and pathogenesis. MCP-1 and RANTES have been shown to induce expression of MMP-3 in both normal and OA chondrocytes [27] and RANTES has been reported to stimulate MMP-1 release in chondrocytes as effectively as did IL-1 $\beta$ [28]. These enzymes are known to degrade chondrocyte extracellular matrix (ECM) which leads to cartilage destruction. MCP-1, RANTES, MIP- $1 \alpha$ and MIP- $1 \beta$ have all been shown to inhibit proteoglycan synthesis in chondrocytes $[27,29]$, a key component of cartilage needed for repair. VEGF expression is absent in adult healthy cartilage but is significantly expressed in OA chondrocytes and may play a role in osteophyte formation [30].

Also interesting is the overall lack of effect from oral supplementation with $\mathrm{NEM}^{\circledR}$ on anti-inflammatory cytokines and chemokines (IL-4, IL-6, IL-10, and TIMP-1) in healthy rats. While IL-4 and IL-6 were below LOQ at baseline, there was only a mild downward trend in IL-10 and TIMP-1 levels-consistent with restoring immune homeostasis following the reductions seen in pro-inflammatory cytokines and chemokines. IL-10 is known to inhibit the production of IL- $1 \beta$ and TNF- $\alpha$ and is overexpressed in OA chondrocytes compared to normal, which is likely the body's attempt to counteract the detrimental effects from these pro-inflammatory cytokines [31]. MMPs are strictly controlled by TIMPs under normal conditions and an imbalance toward MMPs is believed to be the basis for cartilage destruction via ECM degradation in arthritis [32].

$\mathrm{NEM}^{\circledR}$ has been shown in clinical trials to have an effective dose of $500 \mathrm{mg}$ per day. We initially chose to evaluate doses of $6.13 \mathrm{mg} / \mathrm{kg}$ bw/day (Study 1) and 10.0 $\mathrm{mg} / \mathrm{kg}$ bw/day (Study 2) which, following allometric conversion [33], equate to a human equivalent dose (HED) of $59 \mathrm{mg} /$ day and $97 \mathrm{mg} /$ day, respectively, for a $60 \mathrm{~kg}$ person. The number of animals $(\mathrm{n}=3)$ was also small in the preliminary evaluations of inflammatory 
cytokines. These facts, combined with low basal cytokine levels in healthy rats, made it challenging to obtain statistically significant changes following oral supplementation with $\mathrm{NEM}^{\circledR}$. In a number of instances (IL-1 $\beta$ in Study 1 and IL-10 \& RANTES in Study 2), there appeared to be substantial percent reductions in mean cytokine levels that nevertheless failed to reach statistical significance. We therefore set out to employ a rat model in which inflammation was induced (Study 3) to increase the likelihood of observing clearer effects from $\mathrm{NEM}^{\circledR}$ supplementation. We also increased the number of animals $(n=8)$, narrowed the number of cytokines evaluated to five, and increased the doses evaluated to 26.0 $\mathrm{mg} / \mathrm{kg}$ bw/day and $52.0 \mathrm{mg} / \mathrm{kg}$ bw/day (HED: $252 \mathrm{mg} /$ day \& $503 \mathrm{mg} /$ day, respectively).

There was a substantial (39\% - 44\%) and lasting (through 24 hours) reduction in IL- $1 \beta$ in this inflammatory-challenge model (Study 3) at both doses evaluated. And, although not statistically significant, there also appeared to be a substantial (19\% - 32\%) downward trend in TNF- $\alpha$ levels for both doses, as well. These effects on the key mediators of arthritis inflammation provide further supportive evidence to the observed clinical efficacy of NEM ${ }^{\circledR}$. The ability to influence IL- $1 \beta$ and TNF- $\alpha$ in vivo likely also explains at least some of the effects observed in the downstream chemokines (MCP-1, MIP-1 $\alpha$, MIP-1 $\beta$, RANTES, VEGF) in the initial studies. Interestingly, there was a sinusoidal response for the anti-inflammatory cytokine IL-10 over the time-course of this study, in which there was an initial substantial reduction $(28 \%-30 \%)$ at 1.5 hours leading to a substantial increase ( $58 \%$ - 75\%) by 24 hours when compared to controls. This is particularly interesting in the context that nearly all of the cytokines evaluated had returned to near baseline levels by the 24-hour study endpoint in the control animals. The reason for this divergence isn't completely clear, but it may be a result of the delayed timecourse of anti-inflammatory cytokines compared to the rapid time-course of pro-inflammatory cytokines, especially in this particular animal model.

Taken together, these studies demonstrate that oral supplementation with $\mathrm{NEM}^{\circledR}$ can influence both earlyphase pro-inflammatory cytokines like IL- $1 \beta$ and TNF- $\alpha$ (Study 3), as well as later-phase pro-inflammatory cytokines like MCP-1, MIP-1 $\alpha$ \& $\beta$, RANTES and VEGF (Study $1 \& 2$ ). There was also a mild effect on the anti-inflammatory cytokine IL-10 in all three studies. A natural treatment, such as $\mathrm{NEM}^{\circledR}$, which is suitable for chronic inflammatory diseases like arthritis that could potentially avoid the unfortunate side effects of currently available pharmaceutical treatments is of obvious benefit. These studies provide a possible basis for the mechanism of action of $\mathrm{NEM}^{\circledR}$ in vivo and serve as an important step in explaining its observed clinical efficacy seen in mul- tiple human studies.

\section{ACKNOWLEDGEMENTS}

KJR is currently employed by the sponsor of the studies. DPD has served as a paid consultant to the sponsor of the studies. All three studies were sponsored by ESM Technologies, LLC.

\section{REFERENCES}

[1] Harringman, J.J., Ludikhuize, J. and Tak, P.P. (2004) Chemokines in joint disease: The key to inflammation? Annals of the Rheumatic Diseases, 63, 1186-1194. http://dx.doi.org/10.1136/ard.2004.020529

[2] Martel-Pelletier, J., Alaaeddine, N. and Pelletier, J.P. (1999) Cytokines and their role in the pathophysiology of osteoarthritis. Frontiers in Bioscience, 4, d694-d703. http://dx.doi.org/10.2741/Martel

[3] Choy, E.H.S. and Panayi, G.S. (2001) Cytokine pathways and joint inflammation in rheumatoid arthritis. New England Journal of Medicine, 344, 907-916. http://dx.doi.org/10.1056/NEJM200103223441207

[4] Feldmann, M. and Maini, R.N. (2008) Role of cytokines in rheumatoid arthritis: An education in pathophysiology and therapeutics. Immunological Reviews, 223, 7-19. http://dx.doi.org/10.1111/j.1600-065X.2008.00626.x

[5] Brennan, F.M. and McInnes, I.B. (2008) Evidence that cytokines play a role in rheumatoid arthritis. The Journal of Clinical Investigations, 118, 3537-3545. http://dx.doi.org/10.1172/JCI36389

[6] Kokkonen, H., Soderstrom, I., Rocklov, J., Hallmans, G., Lejon, K. and Dahlqvist, S.R. (2010) Up-regulation of cytokines and chemokines predates the onset of rheumatoid arthritis. Arthritis \& Rheumatism, 62, 383-391. http://dx.doi.org/10.1002/art.27186

[7] Dixon, W.G., Suissa, S. and Hudson, M. (2011) The association between systemic glucocorticoid therapy and the risk of infection in patients with rheumatoid arthritis: Systematic review and meta-analyses. Arthritis Research \& Therapy, 13, R139. http://dx.doi.org/10.1186/ar3453

[8] Singh, G., Wu, O., Langhorne, P. and Madhok, R. (2006) Risk of acute myocardial infarction with nonselective non-steroidal anti-inflammatory drugs: A meta-analysis. Arthritis Research \& Therapy, 8, 153-162. http://dx.doi.org/10.1186/ar2047

[9] Masso Gonzalez, E.L., Patrignani, P., Tacconelli, S. and Garcia Rodriguez, L.A. (2010) Variability among nonsteroidal antiinflammatory drugs in risk of upper gastrointestinal bleeding. Arthritis \& Rheumatism, 62, 15921601. http://dx.doi.org/10.1002/art.27412

[10] O’Neil, C.K., Hanlon, J.T. and Marcum, Z.A. (2012) Adverse effects of analgesics commonly used by older adults with osteoarthritis-Focus on non-opioid and opioid analgesics. American Journal of Geriatric Pharmacotherapy, 10, 331-342.

http://dx.doi.org/10.1016/j.amjopharm.2012.09.004

[11] Ruff, K.J., Winkler, A., Jackson, R.W., DeVore, D.P. and Ritz, B.W. (2009) Eggshell membrane in the treatment of 
pain and stiffness from osteoarthritis of the knee: A randomized, multicenter, double-blind, placebo-controlled clinical study. Clinical Rheumatology, 28, 907-914. http://dx.doi.org/10.1007/s10067-009-1173-4

[12] Ruff, K.J., DeVore, D.P., Leu, M.D. and Robinson, M.A. (2009) Eggshell membrane: A possible new natural therapeutic for joint and connective tissue disorders. Results from two open-label human clinical studies. Clinical Interventions in Aging, 4, 235-240. http://dx.doi.org/10.2147/CIA.S5797

[13] Danesch, U., Seybold, M., Rittinghausen, R., Treibel, W. and Bitterlich, N. (Unpublished) $\mathrm{NEM}^{\circledR}$ brand eggshell membrane effective in the treatment of pain associated with knee and hip osteoarthritis: Results from a six-center, open-label german clinical study.

[14] Wong, M., Hendrix, M.J.C., von der Mark, K., Little and C., Stern, R. (1984) Collagen in the egg shell membranes of the hen. Developmental Biology, 104, 28-36. http://dx.doi.org/10.1016/0012-1606(84)90033-2

[15] Baker, J.R. and Balch, D.A. (1962) A study of the organic material of hen's-egg shell. Biochemical Journal, 82, 352-361.

[16] Long, F.D., Adams, R.G., DeVore, D.P., Inventors (2005) Preparation of hyaluronic acid from eggshell membrane. US Patent No. 6,946,551.

[17] Benson, K.F., Ruff, K.J. and Jensen, G.S. (2012) Effects of natural eggshell membrane (nem) on cytokine production in cultures of peripheral blood mononuclear cells: increased suppression of tumor necrosis factor- $\alpha$ levels after in vitro digestion. Journal of Medicinal Food, 15, 360-368. http://dx.doi.org/10.1089/jmf.2011.0197

[18] Systat Software, Inc. http://www.systat.com

[19] Abramson, S.B. and Attur, M. (2009) Developments in the scientific understanding of osteoarthritis. Arthritis Research \& Therapy, 11, 227. http://dx.doi.org/10.1186/ar2655

[20] Sellam, J. and Berenbaum, F. (2010) The role of synovitis in pathophysiology and clinical symptoms of osteoarthritis. Nature Reviews Rheumatology, 6, 625-635. http://dx.doi.org/10.1038/nrrheum.2010.159

[21] Roach, H.I., Aigner, T., Soder, S., Haag, J. and Welkerling, H. (2007) Pathobiology of osteoarthritis: Pathomechanisms and potential therapeutic targets. Current Drug Targets, 8, 271-282. http://dx.doi.org/10.2174/138945007779940160

[22] Sakkas, L.I. and Platsoucas, C.D. (2007) The role of T cells in the pathogenesis of osteoarthritis. Arthritis \& Rheumatism, 56, 409-424. http://dx.doi.org/10.1002/art.22369

[23] Bondeson, J., Wainwright, S.D., Lauder, S., Amos, N. and Hughes, C.E. (2006) The role of synovial macrophages and macrophage-produced cytokines in driving aggrecanases, matrix metalloproteinases, and other destructive and inflammatory responses in osteoarthritis. Arthritis
Research \& Therapy, 8, R187. http://dx.doi.org/10.1186/ar2099

[24] Wenham, C.Y.J. and Conaghan, P.G. (2010) The role of synovitis in osteoarthritis. Therapeutic Advances in Musculoskeletal Diseases, 2, 349-359. http://dx.doi.org/10.1177/1759720X10378373

[25] Martel-Pelletier, J., Tardif, G., Laufer, S. and Pelletier, J.P. (2005) Cytokines and growth factors in the treatment of osteoarthritis: What could be the best disease modifying drugs. Current Medicinal Chemistry-Anti-Inflammatory \& Anti-Allergy Agents, 4, 235-249.

[26] Yuan, G.H., Masuko-Hongo, K., Kato, T. and Nishioka, K. (2003) Immunologic intervention in the pathogenesis of osteoarthritis. Arthritis \& Rheumatism, 48, 602-611. http://dx.doi.org/10.1002/art.10768

[27] Yuan, G.H., Masuko-Hongo, K., Sakata, M., et al. (2001) The role of C-C chemokines and their receptors in osteoarthritis. Arthritis \& Rheumatism, 44, 1056-1070. http://dx.doi.org/10.1002/1529-0131(200105)44:5\%3C10 56::AID-ANR186\%3E3.0.CO;2-U

[28] Alaaeddine, N., Olee, T., Hashimoto, S., CreightonAchermann, L. and Lotz, M. (2001) Production of the chemokine RANTES by articular chondrocytes and role in cartilage degradation. Arthritis \& Rheumatism, 44, 1633-1643.

http://dx.doi.org/10.1002/1529-0131(200107)44:7\%3C16 33::AID-ART286\%3E3.0.CO;2-Z

[29] Vergunst, C.E., van de Sande, M.G.H., Lebre, M.C. and Tak, P.P. (2005) The role of chemokines in rheumatoid arthritis and osteoarthritis. Scandinavian Journal of Rheumatology, 34, 415-425. http://dx.doi.org/10.1080/03009740500439159

[30] Tanaka, E., Aoyama, J., Miyauchi, M., et al. (2005) Vascular endothelial growth factor plays an important autocrine/paracrine role in the progression of osteoarthritis. Histochemistry and Cell Biology, 123, 275-281. http://dx.doi.org/10.1007/s00418-005-0773-6

[31] Iannone, F., De Bari, C., Dell'Accio, F., et al. (2001) Interleukin-10 and interleukin-10 receptor in human osteoarthritic and healthy chondrocytes. Clinical \& Experimental Rheumatology, 19, 139-145.

[32] Ishiguro, N., Ito, T., Ito, H., et al. (1999) Relationship of matrix metalloproteinases and their inhibitors to cartilage proteoglycan and collagen turnover: Analyses of synovial fluid from patients with osteoarthritis. Arthritis \& Rheumatism, 42, 129-136. http://dx.doi.org/10.1002/1529-0131(199901)42:1\%3C12 9::AID-ANR16\%3E3.0.CO;2-4

[33] US Food and Drug Administration (2005) Guidance for industry: estimating the maximum safe starting dose in initial clinical trials for therapeutics in adult healthy volunteers.

http://www.fda.gov/downloads/Drugs/GuidanceComplian ceRegulatoryInformation/Guidances/ucm078932.pdf 